Journal of Social Sciences (COES\&RJ-JSS)

ISSN (E): 2305-9249 ISSN (P): 2305-9494

Publisher: Centre of Excellence for Scientific \& Research Journalism, COES\&RJ LLC

Online Publication Date: $1^{\text {st }}$ April 2017

Online Issue: Volume 6, Number 2 Special, April 2017

http://centreofexcellence.net/J/JSS/JSS\%20Mainpage.htm

\title{
Audio-Visual Approach to Remedial Instruction in Algebra
}

Cynthia C. Honrales

College of Arts and Sciences, Samar State University

Catbalogan City, Samar, Philippines

\begin{abstract}
:
Audio-visual approach is one of the strategies used in instruction to break the monotony of the usual classroom setting. But, is the strategy effective especially if the instruction is remedial in nature? The study sought to find out the effectiveness of teaching Algebra using the audio-visual approach on the achievement of Philippine college students during remedial instruction. It employed a quasi-experimental design particularly the matching-only pretest-posttest control group design to determine the effectiveness of the approach. Two methods were compared - one using the audio-visual approach and the other lecture without the audio-visual materials approach. Results showed that students taking remedial instruction exposed to the audio-visual approach got higher academic performance than those students exposed to the lecture approach without audio-visual materials. The study finds anchorage on the sensory stimulation learning theory and the multimedia learning principles. Thus audio-visual approach was proven effective in learning Algebra. The study recommended that audio-visual approach be used in remedial instruction in mathematics particularly in Algebra. Teachers should be encouraged to use varied instructional materials in teaching the subject. There should be a strong support from the government in providing audio-visual facilities for instruction in Mathematics particularly algebra to college students in the Philippines.

Keywords:

Audio-visual materials, audio-visual approach, multimedia learning principles, remedial instruction

Citation:

Honrales, Cynthia C. (2017); Audio-Visual Approach to Remedial Instruction in Algebra; Journal of Social Sciences (COES\&RJ-JSS), Vol.6, No.2 Special, pp: 1-7.
\end{abstract}




\section{Introduction}

To ensure and maintain quality education, students should possess good technical skills as well as scholastic performance in their preparation for the field training in the real world. Thus, the retention policy requiring students to maintain a grade of at least 2.5 (80\%) for all major subjects including English and Mathematics should be followed. Further, a remedial program in basic English and Mathematics for students who do not meet the qualifying grade of 2.5 shall be required at the end of the semester. Students cannot enrol in higher English and Mathematics subjects without passing the remedial program (CAS Student's Handbook, 2016). Due to the many tasks assigned to a teacher - instruction, research, extension, production and other special assignments, a remedial instruction using audio-visual approach would be a big help to lighten its work. This study is an attempt to find out the effect of audio-visual approach on the performance of students in Algebra in Samar State University, Philippines. Effective learning is important for teachers to consider, and this could be facilitated by sensory stimulation. According to Laird (1985), sensory stimulation learning theory has its basic premise that effective learning occurs when the senses are stimulated. Further, Laird said that $75 \%$ percent of knowledge held by adults is learned through seeing, $13 \%$ by hearing, and $12 \%$ by other senses like touch, smell and taste. By stimulating the senses, especially visual, learning can be enhanced. Furthermore, if multi-senses are stimulated, greater learning takes place. Stimulation through the senses is achieved through a greater variety of colours, volume levels, strong statements, facts presented visually, and use of a variety of techniques and media.

Moreover, according to the multimedia principles, words and graphics are more conducive to learning, rather than just text or graphics alone (Clark, 2011), in the spatial contiguity principle, people learn better when corresponding words and pictures are presented near rather than far from each other on the page or screen, in temporal contiguity principle, people learn better when corresponding words and pictures are presented simultaneously rather than successively (Mayer, 2005), educational videos have been observed to facilitate thinking and problem solving (Mayer, 1990), increase motivation, enhance learning experience (Kearney, 2002) and assist students achieve mastery learning (Galbraith, 2004). As educators, it is our duty to find ways of making students' performance become better. In order to achieve this, we must think of an effective instructional materials to be used in the classroom. One of them is by using modern technology today. According to Brad Henry, "a good teacher can inspire hope, ignite the imagination, and instill the love of learning (Brainy Quote, 2016). Through the teachers' creativity and the new technology at hand, lessons can be organized and utilized in the classroom. Aside from the fact that the use of multimedia is becoming increasingly popular among higher educational institutions as a tool to address inadequacies of traditional plain lecture method of teaching. Although students learn a variety of techniques for solving triangles, manipulating trigonometric expressions, and graphing functions, they miss many opportunities for reasoning and sense making.

A number of authors have called for more meaningful connections in the teaching and learning of trigonometry (Bressoud, 2010; Thompson, 2008; Weber, 2005).Another study was designed to investigate the extent to which using technology for visualization (Arcavi, 2003) would affect students' understanding of the different trigonometric concepts. A mixed method approach (Johnson \& Onwuegbuzie, 2004) consisting of a modified experimental design and a qualitative component was used with two high school precalculus classes. One class was taught by an experienced teacher using traditional 
approach, and the other was taught by a student teacher employing a technology-enhanced approach. In a dissertation conducted by Kadzera (2006) entitled "Use of Instructional Technologies in Teacher Training Colleges in Malawi" has resulted that instructional technologies can improve student learning in teacher training colleges. According to Alaga (2015) Asian learners are highly visual and have advanced level for viewing skill. This has been connotatively concluded by Fjallstrom (2010) that audio-visual is a good complement to written texts. Moreover, according to Arcavi (2003), the use of visualization in Mathematics, enrich the grasping of aspects of people's sense making of mathematics. Despite these evidences on pedagogical advantages brought by technology in teaching-learning process, there were studies conducted that the use of computers simulations in classroom teaching did not entirely change the academic performance of the students (Mirana, 2014), nor documentary films provide positive attitude towards Science subject (Mirana, et al., 2016). In order to clarify these seemingly conflicting findings, it was therefore imperative to conduct a study and find out whether the use of computer or IT-related materials had a positive or negative effect on learning, and in this case, on understanding concepts in Algebra. Thus, the researcher intended to determine and evaluate the effectiveness of audio-visual materials in algebra on the performance of the students in remedial classes.

\section{Statement of the Problem}

The study sought to find out the effectiveness of teaching Algebra using the audio-visual approach on the achievement of Philippine college students during remedial instruction. It also validated the audio-visual materials in terms of clarity of presentation, duration, language used, appropriateness of graphics used and clarity of the audio.

\section{Research Design of the Study}

In this study I employed a quasi-experimental design particularly the matching-only pretest-posttest control group design (Fraenkel and Wallen, 2007) to determine the effectiveness of the materials. Two methods were used: the audio-visual materials in algebra for one group and the other without the audio-visual materials. The materials were submitted for expert validation and consultation with different mathematics professors of the Samar State University for careful analysis and scrutiny. Their comments and suggestions were considered for the enhancement of the materials.

\section{Significance of the Study}

This study was conducted to address the need for a functional remedial program in mathematics for Philippine college students. The result of this study would inform them to focus more attention on the least learned skills in Mathematics so that they would be able to relearn the skills in Algebra where there is less or no mastery learning using the audio-visual materials. Thus, the low-achievers in the class could be able to reach the level of standard performance. The findings of this study would serve as baseline data for remediation and help find ways to solve students' low achievement rather than totally neglecting them. The use of the audio-visual materials would help the teacher in her teaching, thus giving her materials and enough time to guide and assist the low achievers until they can reach the level of the achievers and even the over-achievers in the class. The audio-visual materials could also provide ready reference for both the students and the teachers when there is not enough supply of textbook and related references. The results of this study would give the administrators insights into the needs and problems of the teachers along audio-visual instructional materials, thereby making them supportive by 
way of providing teachers with modern facilities on remediation of mathematics instruction. The findings of this study would help parents intensify their awareness where guidance and assistance is necessary with maximum care and understandings, thus helping their children develop right study habits. They may also be able to know the learning needs and difficulties of their children particularly in Algebra. The results of this study would serve as inputs to the improvement of remedial instruction particularly for the low achievers. Audio-visual approach may also be considered in teaching Algebra and allied subjects. The results of this study could provide future researchers rich source of materials as inputs or bases for them to conduct further studies related to audio-visual approach in remedial instruction.

\section{Method of Procedure}

Sample students from freshmen Bachelor of Science in Information Technology (BSIT) class were selected purposively and assigned into two groups. The grade of the student in their midterm was the basis in matching the students and in assigning them into two groups, of which one was the control group (without the audio-visual materials) and the other, the experimental group (with the audio-visual material). In order to eliminate bias, the mean of the midterm grades of the samples for the control group and the experimental group were equated. The instruments and tools used in this study were the achievement test, the pretest/posttest, the audio-visual materials in algebra, and documentary analysis specifically the grades of students. The researcher-made achievement test is a 70-item teacher-made test used in the pretest and posttest. It underwent item analysis which assessed the topics that covered Linear and Quadratic Functions. The test itself was used to determine the level of achievement in algebra of the BSIT students who previously took the course.

\section{Collection of Data}

As their mathematics instructor, I used documentary analysis in examining the midterm grades of the students in Math 101. The grades became the basis in selecting and balancing the participants of the study. I conducted the pre-test to the two groups of samples the same day but of different schedule on the early part of July to determine the initial knowledge of the students on the topics Linear and Quadratic Functions. I saw to it that factors that may affect the result such as honesty, seating arrangement, time, lighting, and ventilation were controlled. I conducted formal lesson to the control group without the audio-visual materials. I facilitated also in the conduct of the audio-visual instruction to the experimental group. I arranged the schedule of classes since I had the control of the students' schedule. The experiment started during the first semester of school year 2015-2016 where they are taking the subject College Algebra. After the experimentation, the post-test was administered to the two groups of samples. The post-test determined the knowledge and skills the students have acquired from the two different approaches to teaching - without the audio-visual materials and with the audio-visual materials. The factors that may affect the result of the post-test such as honesty, classroom ambience, time, light, and ventilation were controlled.

\section{Treatment of Data}

Statistical Package for Social Science (SPSS, Ver. 16.01 WIN RC, S/N 5057979) was used to treat all the quantitative data like the mean and standard deviation and the $\mathrm{z}$-test. Correlation analysis was used to assess the relationship of the effectiveness of the audiovisual materials. In addition, the reliability test was calculated using Cronbach's alpha. 
Findings

Table 1. Validity of the Audio-Visual Materials in algebra

\begin{tabular}{lcl}
\hline Indicators & Xm & Interpretation \\
\hline Clarity of Presentation & 3.64 & TVGE \\
Duration & 3.2 & TGE \\
Language Used & 3.6 & TVGE \\
Appropriateness of Graphics Used & 3.59 & TVGE \\
Clarity of the Audio & 3.32 & TGE \\
Grand Mean & 3.44 & TGE \\
\hline
\end{tabular}

Reliability Statistics: Cronbach's Alpha 0.780113322

Legend: 3.51 - 4.00 To a Very Great Extent (TVGE); 2.51 - 3.50 To a Great Extent (TGE); 1.51 - 2.50 To a Moderate Extent (TME); 1.00 - 1.50 To the Least Extent (TLE).

To find out the validity and reliability of the audio-visual materials, Cronbach's alpha was used, and it showed a good level of internal consistency for the audio-visual materials in algebra.

Table 2. Comparison Between the Pre-test and Post-test Results of the Control and the Experimental Groups

\begin{tabular}{lccl}
\hline & Control Group & Experimental Group & \\
\hline Pre-test & & & \\
Mean & 15.9 & 16.8 & \\
SD & 5.63 & 6.85 & -0.56 \\
z-value & & 0.5784 \\
p-value & & Not Significant \\
Evaluation & & & \\
Posttest & & & \\
Mean & 22.37 & 29.07 & -3.94 \\
SD & 7.01 & 6.14 & 0.00001 \\
z-value & & & Significant \\
p-value & & & \\
Evaluation & & &
\end{tabular}

To determine the significant difference between control and experimental groups, the ztest value is found to be not significant. However, in the post-test, the difference in the scores of the two groups is found to be highly significant.

\section{Discussion}

Since there is significant difference between the pre-test and post-test score of the experimental group, the result indicates that the use of audio-visual materials in remedial instruction in algebra is indeed effective. This finding is similar to the study of Fjallstrom (2010) that audio-visual is a good complement to written texts, and even that of Arcavi (2003), on the use of visualization in Mathematics, and in grasping of aspects of people's sense- making of the subject. Relatedly, in the field of language learning, audio-visual materials is also found to improve learning in language particularly among Asians (Alaga, 2016). Thus, this finding further elucidates the theory of Laird (1985) on the impact of sensory stimulation on learning. Integrating audio-visual in teaching methods and 
strategies made the lesson more enjoyable and appealing which could make a difference in a usually abstract, tedious and boring mathematics subject as algebra.

\section{Conclusion and Implication of the Study}

The audio-visual approach to remedial instruction in Algebra is more effective than the traditional approach. The study showed evidence that audio-visual approach can enhance learning among students because it improves achievement level in mathematics. Having determined the highly significant difference between the computed mean difference of the control and experimental groups, it became evident that the latter which was exposed to the audio-visual materials achieved higher scores in algebra. The effectiveness of the audio-visual materials are found to improve learning through enhanced visual stimulation especially among Asian learners (Alaga, 2010), and as a good complement to written texts (Fjallstrom, 2010).

The study recommends that teachers should be encouraged to use varied instructional materials such as the audio-visual devices in algebra. Towards this end, there is a need to have a strong support from the school administration in providing the audio-visual facilities for instruction so that all instructional materials be fully utilized by the instructors and students. The results of the study implied that remedial instruction using the audio-visual approach was very necessary to make low achievers come up to the level of the achievers.

\section{Acknowledgement}

Sincerest gratitude is extended to Prof. Pedro S. Cabrales at Samar State University, for improving the content and format of this paper.

\section{References}

Alaga, Nathalie Ann C. (2016). Media Exposure for an Enhanced Communicative ESL Instruction. Research Journal of English Language and Literature. 4(1): 145- 151. India

Arcavi, A. (2003). The Role of Visualization in the Learning of Mathematics. Educational Studies in Mathematics, 52: 241-251

Brainy Quote. (2016). Brad Henry:retrieved from www.brainyquote.com/Bradhenry/July 29, 2016

Bressoud, D. M. (2010). Historical Reflections on Teaching Trigonometry. Mathematics Teacher, 104(2), 106-112.

CAS Student's Handbook, Samar State University, 2016

Clark, R. C., \& Mayer, R, E. (2011). E-Learning and the science of instruction: proven guidelines for consumers and designers of multimedia learning ( $3^{\text {rd }}$ ed.) San Francisco, CA: John Wiley \& Sons

Fjallstrom, Eva. (2010). Film and Streaming Media as Resources in English Teaching. Retrieved from http:/www.google.scholar.com

Fraenkel JR and Wallen NE. (2007). How to design and evaluate research in education. New York, NY: McGraw Hill, pp. 277-278

Galbraith, J. (2004). Active viewing: and oxymoron in video-based instruction? Society for Applied Learning Technologies Conference, designer.50g.com/docs/Salt_2004.pdf Johnson, R., \& Onwuegbuzie, A. (2004). Mixed Methods Research: A Research Paradigm Whose Time Has Come. Educational Research, 33(7), 14-26.

Kadzera, Clemence Michael (2006). Use of Instructional Technologies in Teacher Training Colleges in Malawi, Blacksburg, Virginia. Accessed November 10, 2014 
Kearney, M. (2002). Using digital video to enhance authentic technology-mediated learning in science classrooms. Paper presented at the Australian Computers in Education Conference, Hobart. Available: http://www.tasite.tas.edu.au/acec2002

Laird, D. (1985). Approaches to training and development Addison-Wesley, Reading, Mass.

Mayer, R, Gallini, J (1990). When is an illustration worth ten thousand words? Journal of Educational Psychology, 82(6) (715-726) Available: http://www.uq.edu.au/teach/video-teach-learn/ped-benefits.html

Mayer, R. E. (2005). Principles for managing essential processing in multimedia learning: Coherence, signalling, redundancy, spatial contiguity and temporal contiguity principles. In R. E.

Mayer (Ed.) Cambridge handbook of multimedia learning (pp. 183-200). New York: Cambridge University Press.

Mirana, V. et. al. (2016). Effects of Documentary Films on Students' Attitude towards Science: A Pretest and Posttest Study. International Conference Proceedings of URUAE and ICEHM, p. 191

Mirana, V. (2014). Effects of Computer simulations and Constructivist Approach on Students' Epistemological Beliefs, Motivation and Conceptual Understanding in Physics. International Conference Proceedings of URUAE and ICEHM. p. 197

Smith III, J., \& Thompson, P. W. (2008). Quantitative Reasoning and the Development of Algebraic Reasoning. In J.J. Kaput, D. Kaput. Carraher \& M. L. Blanton (Eds), Algebra in the Early Grades (pp. 95-132). New York, NY: Lawrence Erlbaum Associates Thompson, P. W. (2008). Conceptual Analysis of Mathematical Ideas: Some Spadework at the Foundations of Mathematics Education. In O. Figueras, J. L. Cortina, S. Alatorre, T. Rojano \& A. Si pulveda (Eds), Proceedings of the Annual Meeting of the International Group for the Psychology of Mathematics Education (Vol. 1, pp 45-64)

Wang, Victor C. X. (2014). Handbook of Research on Education and Technology in a Changing Society. Vol II, IGI Global.

Weber, K. (2005). Students' Understanding of Trigonometric Functions. Mathematics Education Research Journal, 17(3), 91-112.

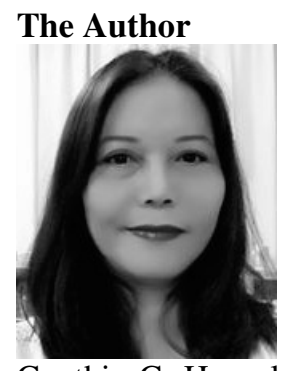

Cynthia C. Honrales, born on February 5, 1964 at Catbalogan City, Samar, Philippines. She is an assistant professor handling mathematics subjects at College of Arts and Sciences, Samar State University, Catbalogan City. She obtained her bachelor's and master's degrees at Samar State University with major in Mathematics. She presented paper on IT-Based Audio-Visual Materials in Trigonometry at the 2016 International Higher Education Research Forum at Tagaytay International Convention Center. 